\title{
Navigating the Business Model Maze
}

\author{
Bill Schulze (University of Utah)
}

KEYWORDS: Entrepreneurship, Innovation, Product Development, Strategy.

\section{By William Schulze, Robert Wuebker, and Gerry Campbell}

Innovative business models are wonderful ... but using the wrong business model to re-imagine your business can be dangerous! A look at business model evolution confirms that each model was designed to solve a specific set of problems - problems you may, or may not face. We examine the evolution of four popular startup models, and provide a simple set of rules that will allow you to choose the right one for you.

Business models are all the rage. A seemingly everincreasing flow of books, blogs and seminars promise us that a "systematic" approach to business model innovation will allow you to find ways to re-invent an existing business, develop new products, find customers, leverage technology and increase profits. Better yet, we are encouraged to believe that diligent and precise application of these techniques will allow us to develop a "game-changing" business model - one that undermines the competition but leaves the innovator in a position of strength and enduring competitive advantage. But what should we make of these promises? Do "business model innovation" strategies work? And which one, among the many, is right for me?

Innovative business models do work. Apple revolutionized the music industry by wrapping a service (iTunes) around a product (the iPod), and used the same model to revolutionize the smartphone and tablet markets with the iPhone and iPad. Amazon redefined online retailing by leveraging their online platform and remarkable logistical skills across hosts of marketplaces, not just books. Zipcar created a reasonable substitute for car ownership for city dwellers, and FedEx proved that just about anything could get there overnight.

But business model innovation can be risky, and in some instances, fatal. Ratan Tata, who created a radical new business model in order to produce and market a $\$ 2000$ car in India was widely praised, but is struggling to provide quality at low cost. Meanwhile, competitors like Suzuki have closed the gap between themselves and the Nano with new lines of low-priced vehicles. Webvan confirmed that the online grocery market model did not scale and Delta and United's experiences with Song and TED proved that Southwest's business model is very difficult to duplicate.

But how, and why, do these mistakes happen?

\section{Two Approaches for Breakthroughs}

Innovative business models are not simply mashups of old and new ways of doing business, but rather are themselves the product of new ways of thinking about business.

The first, and most familiar strand of this literature, called "business model innovation," uses business model logic to break existing businesses into related blocks of value-generating activity, and challenges the manager to use those building blocks to find new ways of conducting existing business or to create new products and markets for them. Examples of this approach include recent HBR articles by Clay Christiansen and Joan Magretta, as well as books by authors like Mark Johnson (Seizing the White Space), Tim Brown (Change by Design), and Mark Osterwalder (Business Model Generation). What is interesting about business model innovation is that its tools and techniques were developed for use by existing corporations - not startups.

The second, less familiar strand of the literature, which we call business model discovery, describes different processes that the aspiring entrepreneur or new product developer can use to create valuable new businesses and products. What is interesting about this literature is that it documents how technology has fundamentally altered the challenge of testing a product concept and launching a business. The newest discovery model, 
"Build, Beta, Pivot," or BBP, was pioneered by Google and Facebook and used to create Gmail and now, Google+.

Each approach, however, must be used wisely, because each is based on a set of assumptions that can lead to serious miscalculation if overlooked. The logic of disruptive technology, for example, engenders a sense of urgency, since it warns that unsuspecting established companies can quickly be left behind. Yet new markets are not always more attractive than the old ones, and even most the radical technologies (e.g., VOIP or voiceover-internet-protocol in 1996) may turn out in time to be just as accessible to incumbents (e.g., AT\&T \& Verizon) as newcomers (e.g., Skype \& Vonage).

Using the wrong discovery model can also be dangerous because different discovery models were created to mitigate different types of risks, which changed over time with technology and with the evolution of the marketplace. For example, the traditional business plan emerged from a marketplace in which capital was scarce and technological hurdles took significant time and energy to overcome. The traditional business plan, however, was not well adapted to the dot.com era -- a period in which technological change was rapid and capital was abundant -- or to the postdot.com period, when demand for scarce engineering talent made its wise use critical. Changing entrepreneurial and technological challenges thus motivated entrepreneurs to experiment with new solutions to existing problems.

\section{How Business Models Evolve}

Microsoft reduced product development costs by introducing the practice of "beta-testing" products on its customer (which sped product development while shifting the cost of debugging from Microsoft to endusers). Rising customer frustration with this practice motivated Microsoft to pioneer concepts like minimal viable product, or MVP, to help them identify the appropriate intervals at which new software products should be released. Smart entrepreneurs soon realized that they could use MVP to speed product development. They also soon recognized they could blend MVP with lessons learned about lean manufacturing (a concept that emerged in the USA in the late 1980s) and reduce both the technological AND financial risk of their new ventures. Over time, entrepreneurs merged sets of related newly developed business practice with established practice to create new ways of doing business. The "lean startup" model, recently popularized by Eric Reis, can be traced to specific business practices (and consulting models) that were pioneered during the late 1990's.

By the early 2000's, however, rapidly growing network capacity spawned a new primordial market (i.e., enterprise software), new facilitating technologies (e.g., Linux, Apache, MySQL and PHP or the LAMP stack of open source software) and hence, new problems and the need for new strategies for business model discovery. For example, an engaging software entrepreneur, Steve Blank, used MVP to help him tailor existing products to the needs of existing customers. He soon recognized that the same process, a process that he and Frank Robinson later called "Sell-Design-Build" or SDB, could be used to create new products for existing customers. SDB was distinctive because it used scientific research methods to help them rigorously identify problems that new products could solve. What was novel about $t$ SDB was its focus on market validation - proving a viable market exists for proposed products before starting the product development process.

The next primordial market, internet search, created a platform on which Google and Facebook, among others, removed even more risk from the product development process by using $A / B$ testing - a process that was initially used to refine existing products -- to design new products. (While A/B testing was used by software companies in the 1990's, the technology needed to leverage it wasn't available until 2004. To our knowledge, AOL pioneered real-time $\mathrm{A} / \mathrm{B}$ testing in 2004-2005). Today, improved data analytics and continuous integration have made it possible for even small firms to release competing versions of their software products and to base feature selection decisions on data obtained through actual use by its customers. This new approach, which we call BuildBeta-Pivot (or BBP) is distinctive because it is directly involves the customer in the product development process. It also differs from SDB since it begins with release of a beta version of the new product, not market research.

The introduction of iOS, the language used to program apps, further spurred BBP's adoption. Since 2008, manufacturing and distribution methods have evolved to the point where established companies, as well as entrepreneurs, now routinely test product concepts by 
marketing virtual versions of their products over the web, or even producing and selling "beta" versions of physical products via a variety of distribution channels, including "pop-up" and flagship stores. (What is common to both is that they are primarily used to testmarket product and concepts: neither are reliable money-makers). These trends are being reinforced by venture capitalists, some of whom, like Fred Wilson, cofounder of Union Square Ventures, are increasingly unwilling to fund supplicants who lack verifiable data that demonstrates the product has traction in its target market.

\section{Emerging Models}

As we speak, new business model strategies are emerging that are better suited than BBP to today's marketplace. Emerging business models tackle the problems and risks created by BPP, such as diminishing data quality due to the proliferation of faux product sites and the commensurate decline in customer willingness to engage these "vendors." One company, Kickstarter, solves the data integrity problem by asking customers to make a small investment in the new firm, usually in return for a very small equity stake and a beta version of the product. Apple and other platforms have raised the bar for new apps by insisting they pass performance tests before releasing them to the iTunes Store. New practices are also emerging to reduce the very high opportunity costs created by a "bad" pivot or two. For example, after his unfortunate BBP experience at Twitter (which pivoted away from multiple opportunities to monetize its traffic), Frank Dorsey (SQUARE) now disciplines his BBP process by using dashboards to rigorously evaluate incoming data. These practices have become widespread. As an entrepreneur recently told us that, "there's not a single part of our website or application that doesn't have a number tied to it!"

We hope it is now evident that business innovation and business discovery models differ. Innovation approaches give the user the challenge of breaking the existing business unit into related value-generating blocks of activities and assets and creatively investigating how they might be re-assembled in ways that create greater value for the firm or customer. Different innovation models stress different threats to the existing organization, including disruptive technologies, shifting market demand, competition and customer characteristics. In the main, the principles of business strategy (newly reconstituted using the business model as its analog) are used to guide the evaluation and selection process.

In contrast, business discovery models prescribe sequences of activities aimed at "discovering" valuable products and markets, and challenge entrepreneurs to create a business model that will allow them to capture value from them. Discovery model selection is driven by classification of the nature of the risks faced by the entrepreneur. In general, discovery models use the "scientific" model and hypothesis testing as their analog, and argue that the task of the entrepreneur is to resolve uncertainty - to answer unknowns - about the assumptions that underpin their product concept. While all discovery models suggest that questions should be answered in order of the magnitude of the threat posed, and that the questions should change with each successive set of answers, the assumptions on which they are based differ. Minimal viable product principles, for example, allow one to economize on product development costs while accelerating the pace at which new products can be brought to the market for test. This approach can be useful in situations where viable markets exist and the core challenge is to identify the bundle of product features that will determine market success. It also assumes that product feasibility must to be demonstrated before customer validation can occur. Sell-Design-Build models, on the other hand, begin with the assertion that one does not need a "real" product to test a market. Rather, entrepreneurs can discover product concepts and test their viability by interviewing prospective customers about their needs. Ideally, SDB does not start product development until customers are secured. BBP, in contrast, starts with a product that is released in beta form to the market. The product is then iteratively revised, sometimes on a daily basis, until sufficient data is obtained to resolve major uncertainty about product feasibility, feature sets, market scale and so on.

The business model is a powerful concept, but "one size does not fit all." Managers need to choose carefully and wisely in order to navigate the business model maze. In future posts, we will detail four business discovery models - traditional, Minimum Viable Product, SellDesign-Build, and Build-Beta-Pivot - and discuss the merits of each. We will also address at some length what we mean by "testing," and why its best practice bears little if any resemblance to the testing processes familiar from the sciences. 
Additional Search Terms: Structuring my business, business analysis, what to sell, product development, testing 